\title{
Asymptomatic Bacteriuria and Their Antimicrobial Susceptibility Pattern Among Pregnant Women Attending Antenatal Clinics at Mizan Aman Town, Southwestern Ethiopia
}

\author{
Abera Kumalo ${ }^{1, ~ *}$, Mezmur Tadesse ${ }^{2}$ \\ ${ }^{1}$ Department of Medical Laboratory Science, Wolaita Soddo University, Sodo, Ethiopia \\ ${ }^{2}$ Department of Biomedical Sciences, Mizan-Tepi University, Mizan Aman, Ethiopia \\ Email address: \\ aberak2000@gmail.com (A. Kumalo),mezmurnunu@yahoo.com (M. Tadesse) \\ ${ }^{*}$ Corresponding author
}

To cite this article:

Abera Kumalo, Mezmur Tadesse. Asymptomatic Bacteriuria and Their Antimicrobial Susceptibility Pattern Among Pregnant Women Attending Antenatal Clinics at Mizan Aman Town, Southwestern Ethiopia. European Journal of Clinical and Biomedical Sciences. Vol. 6, No. 4, 2020, pp. 56-62. doi: 10.11648/j.ejcbs.20200604.12

Received: August 4, 2020; Accepted: August 20, 2020; Published: September 3, 2020

\begin{abstract}
Introduction: Failure to identify asymptomatic bacteriuria (ASB) is responsible for its improper clinical management. This may lead to severe health complications during pregnancy. However, little is known about antimicrobial susceptibility of ASB in Ethiopian pregnant women. Therefore, the study was conducted to assess the prevalence of ASB and its antimicrobial susceptibility pattern in the target population. Methods: A cross-sectional study was conducted during September-December of 2017 at Mizan-Aman town, south-western Ethiopia among pregnant women $(\mathrm{n}=260)$ attending antenatal clinics. $10 \mathrm{ml}$ of clean- catch midstream urine was collected and cultured on Cysteine Lactose Electrolyte Deficient agar. Bacterial isolates were identified using Gram staining, colony morphology, and biochemical analysis. Antibiotic susceptibility was assessed by Kirby-Bauer disc-diffusion method. Logistic regression was employed for association analysis. Results: The prevalence of urinary tract infection was $10.3 \%$. ASB was significantly associated with second trimester $(\mathrm{AOR}=5.61[1.40-22.45] ; p<0.05)$ and history of urinary tract infection $(\mathrm{AOR}=12.47$ [3.91-39.82]; $p<0.001)$. Escherichia coli were most prevalent pathogen and gram positive bacteria comprised majority of the overall isolates (63\%). The Gramnegatives were more resistant with susceptibility rates of $11.8 \%, 29.4 \%$, and $35.3 \%$ for ampicillin, nalidixic acid and chloramphenicol respectively. The susceptibility rates of Gram-positives were $100 \%, 80 \%, 70 \%$ for ciprofloxacin and kanamycin, co-trimoxazol and ceftriaxone and gentamycin respectively. Multidrug resistance ( $\geq 2$ drugs) was seen in $81.5 \%$ of isolates. Conclusion: In generally, pregnant women with ASB may have serious consequences on both mother and fetus. Since in this study the locale specific heterogeneity in ASB prevalence, type and number of bacterial species, dominant bacterial species, antibiotic susceptibility pattern and multidrug resistance was observed. Therefore, it is important to screen all antenatal women for asymptomatic bacteriuria at their first prenatal visit; preferably in first trimester as well as antimicrobial susceptibility testing should be performed for management of ASB among pregnant women.
\end{abstract}

Keywords: Asymptomatic Bacteriuria, Pregnant Women, Antenatal, Antimicrobial Susceptibility, Ethiopia

\section{Introduction}

Asymptomatic bacteriuria (ASB) is characterized by the presence of actively multiplying bacteria in the urinary tract excluding the distal urethra without obvious symptoms. Isolation of $\geq 10^{5} \mathrm{cfu} / \mathrm{ml}$ of a specific bacterial species in midstream urine confirms ASB [1-2]. Women are at a higher risk of Urinary tract infection (UTI) and its recurrent episodes [3-4]. It affects up to $10 \%$ pregnant women across globe. Local prevalence of ASB is the primary determinant of the incidence of UTI [5]. The apparent reduction in immunity during pregnancy seems to encourage the growth of 
opportunistic microorganisms [6-7]. Pregnancy enhances the progression of ASB to symptomatic bacteriuria. This may lead to increased risk of pyelonephritis (20-to-50-fold). These may adversely affect obstetric outcome such as premature delivery, birth weight and fetal mortality rates [4, 8-10]. In spite of this high disease burden, failure to identify ASB during pregnancy is observed among health personnel managing pregnant women [11-13].

The kidneys of the pregnant women excrete waste products of her body as well as those of the foetus. This dual excretory load together with increased incidence of risk factors i.e. ASB associated UTI increase vulnerability to medical complications [14-15]. Approximately 90\% of women experience pregnancy associated hydronephrosis. This is progesterone ureteral dilatation begins at week 6 and reaches its peak between weeks 22 to 24 . Ureteral dilatation, increased bladder volume and decreased bladder tone, along with decreased ureteral tone, contribute to increased urinary stasis and ureterovesical reflux. Additionally pregnant women develop glycosuria, which may promote bacterial growth in the urine. These factors contribute to the development of asymptomatic UTI during pregnancy [13$15]$.

The frequency of isolated pathogens, prevalence and antimicrobial resistance patterns varies in different geographical regions [16-20]. Both gram negative and grampositive bacteria colonize the vaginal introitus and periurethral area. Usually the gram negatives are more prevalent in ASB but the relative prevalence of all other bacterial species causing the ASB varies widely $[6,13,17-$ 20]. The proper medical interventions including antimicrobial prescription to manage the ASB and associated UTI requires locale specific baseline data related to the type and/strain of the pathogens, their relative prevalence, overall prevalence of ASB and/or UTI and anti-microbial resistance pattern. These information help in providing timely intervention, decrease burden of infection and manage globally increasing trend of anti-microbial resistance. The comprehensive ASB mapping across geographical locales in developing third world countries are indispensible. Therefore this study was conducted to determine the prevalence of ASB and their susceptibility pattern among pregnant women at Mizan Aman town, South-western Ethiopia.

\section{Methods}

\subsection{Study Design and Participants}

A cross-sectional study using systematic sampling was performed during September-December of 2017 at General Hospital and Health Center of Mizan Aman town, Southwestern Ethiopia. Pregnant women $(n=260 ; 23.8 \pm 3.99$ years) attending antenatal clinics (ANC) and without established symptoms of urinary tract disorders/ antibiotic treatment completed the study. Socio-demographic and clinical history data were collected using a structured questionnaire tool. The study was approved by the Research committee and Publication office, Mizan-Tepi University, Mizan, Ethiopia. Informed written consent was given by the participants.

\subsection{Sample Collection and Microbiological Assay}

A clean-catch mid-stream urine samples $(10 \mathrm{ml})$ were collected in sterile wide mouthed glass bottles. These were inoculated on Cysteine Lactose Electrolyte Deficient medium (CLED) using calibrated wire loop $(0.001 \mathrm{ml})$ samples. Bacterial counts and (bacterial count $\geq 1 \times 10^{5} / \mathrm{ml}$ ) were determined. Single colonies from culture plates with significant bacteriuria were suspended in nutrient broth. These were sub-cultured on Blood agar and MacConkey agar (Oxoid, Ltd) and incubated aerobically at $37^{\circ} \mathrm{C}$ for $24-48 \mathrm{hrs}$ [21-22].

\subsection{Isolation and Identification of Bacterial Pathogens}

Bacterial identification was done by their characteristic appearance on medium, Gram staining reaction and pattern of biochemical reactions. Members of the family Enterobacteriaceae were identified by indole production, $\mathrm{H}_{2} \mathrm{~S}$ production, citrate utilization, motility test, urease test, oxidase, carbohydrate utilization tests. For Gram-positive bacteria coagulase and catalase tests were used [21-22].

\subsection{Antimicrobial Susceptibility Testing}

Antimicrobial susceptibility testing performed on MuellerHinton agar plates using Kirby Bauer diffusion technique according to the criteria of the Clinical and Laboratory Standards Institute (CLSI). From a pure culture 3-5 selected colonies of bacteria wereinoculated into saline $(5 \mathrm{ml})$ and mixed gently to a homogenous suspension. The turbidity of the suspension was matched to a 0.5 McFarland standard [2324]. The drugs used in disc diffusion test were in the following concentrations: Ampicillin (AMP) (10 $\mu \mathrm{g})$, Amoxicillin-Clavulanic Acid (AMC) $(30 \mu \mathrm{g})$, Ceftriaxone (CRO) $(30 \mu \mathrm{g})$, Naldixic Acid (NA) $(30 \mu \mathrm{g})$, Ciprofloxacin (CIP) $(5 \mu \mathrm{g})$, Chloramphenicol (C) $(30 \mu \mathrm{g})$, Cefoxitin (CXT) $(30 \mu \mathrm{g})$, Doxycycline (DO) $(30 \mu \mathrm{g})$, Gentamicin (CN) $(10 \mu \mathrm{g})$, Kanamycin $(\mathrm{K})(30 \mu \mathrm{g})$ and TrimethoprimSulphamethoxazole (TMP- SXT) (1.25/23.75 $\mu \mathrm{g})$ [21-22].

Culture Media were prepared according to manufacturer's instruction. Sterility of culture media was checked by incubating $5 \%$ of the batch at $35-37^{\circ} \mathrm{C}$ overnight and observing the bacterial growth. The quality of culture media and antimicrobial susceptibility were checked using standard reference strain of $P$. aeruginosa (ATCC-27853), S. aureus (ATCC-25923) and E. coli (ATCC-25922).

\subsection{Data Analysis}

Statistical analysis was performed by using SPSS version 20.0 (SPSS Inc. Chicago). Descriptive analysis and test of differences were employed. Multiple logistic regression was used to determine the predictors of ASB. 


\section{Results}

\subsection{Socio-demographic Characteristics}

The socio-demographic characteristics of the participants are summarized in Table 1. Majority of the pregnant women were married $(97.7 \%)$ and urban dwellers $(79.6 \%)$. The age of the pregnant women ranged from 16 to 39 years with median age of 24 years and mean of $23.8 \pm 3.99$ years. Regarding occupational status of participants, $127(48.8 \%)$ were housewives followed by farmers $48(18.5 \%)$ and government employees $43(16.6 \%)$.

Table 1. Prevalence of asymptomatic UTI and sociodemographic characteristics of pregnant women (N=260) at Mizan-Aman town, South-western Ethiopia, from September-December of 2017.

\begin{tabular}{llll}
\hline Characteristics & Number tested (\%) & Positive (\%) & Negative (\%) \\
\hline Health Facility & $197(75.8)$ & $24(12.2)$ & $173(87.8)$ \\
Mizan Aman Hospital & $63(24.2)$ & $3(4.8)$ & $60(95.2)$ \\
Mizan Aman Health Centre & & & $56(83.6)$ \\
Ages (years) & $67(25.8)$ & $11(16.4)$ & $108(90.0)$ \\
$16-20$ & $120(46.2)$ & $12(10.0)$ & $61(93.8)$ \\
$21-25$ & $65(25.0)$ & $4(6.2)$ & $5(100.0)$ \\
$26-30$ & $5(1.9)$ & $--(-)$ & $3(100.0)$ \\
$31-35$ & $3(1.2)$ & $--(--)$ & $229(90.2)$ \\
$36-40$ & $254(97.7)$ & $25(9.8)$ & $4(66.6)$ \\
Marital status & $6(2.3)$ & $2(33.4)$ & $185(89.4)$ \\
Married & & & $48(90.6)$ \\
Other & $207(79.6)$ & $22(10.6)$ & $42(87.5)$ \\
Address & $53(20.4)$ & $5(9.4)$ & $39(90.7)$ \\
Urban & & & $7(87.5)$ \\
Rural & $48(18.5)$ & $6(12.5)$ & $12(100)$ \\
Occupation & $43(16.6)$ & $4(9.3)$ & $112(88.2)$ \\
Farmer & $8(3.0)$ & $1(12.5)$ & $21(95.5)$ \\
Government employee & $12(4.6)$ & $0(0)$ & $136(87.8)$ \\
Student & $127(48.8)$ & $15(11.8)$ & $27(90)$ \\
Unemployed & $22(8.5)$ & $1(4.5)$ & $23(100)$ \\
Housewife & & & $14(87.5)$ \\
Private business & $155(59.6)$ & $19(12.2)$ & $3391.7)$ \\
Monthly income (Birr) & $30(11.5)$ & $3(10)$ & $0(0)$ \\
$<500$ & $23(8.9)$ & $2(12.5)$ & $3(8.3)$ \\
$501-1000$ & $16(6.1)$ & & \\
$1001-1500$ & $36(13.8)$ & & \\
$1501-200$ & & & \\
$>2000$ & & & \\
\hline
\end{tabular}

\subsection{Associated Risk Factors}

Prevalence of ASB in this sample of pregnant women was $10.4 \%$. It was associated with second trimester $(\mathrm{AOR}=5.61[1.40-$ 22.45]; $\mathrm{p}<0.05)$ and history of UTI $(\mathrm{AOR}=12.47$ [3.91-39.82]; $<0.001)$.

Table 2. Multiple linear regression analysis: Predictors of asymptomatic bacteriuria of pregnant women (N=260) at Mizan-Aman town, South-western Ethiopia, from September-December of 2017.

\begin{tabular}{|c|c|c|c|c|c|c|}
\hline \multirow[t]{2}{*}{ Variable } & \multicolumn{2}{|c|}{ Asymptomatic bacteriuria } & \multirow[t]{2}{*}{ COR $(95 \%$ CI $)$} & \multirow[t]{2}{*}{ P-value } & \multirow[t]{2}{*}{$\operatorname{AOR}(95 \% C I)$} & \multirow[t]{2}{*}{ P-value } \\
\hline & No Number (\%) & Yes Number (\%) & & & & \\
\hline \multicolumn{7}{|l|}{ Age } \\
\hline $16-20$ & $56(83.6)$ & $11(16.4)$ & 1 & & & \\
\hline $21-25$ & $108(90.0)$ & $12(10.0)$ & $0.57(0.23-1.36)$ & 0.204 & & \\
\hline $26-30$ & $61(93.8)$ & $4(6.2)$ & $0.33(0.10-1.11)$ & 0.073 & & \\
\hline $31-35$ & $5(100.0)$ & - - (--) & $0.00(0.00----)$ & 0.999 & & \\
\hline $36-40$ & $3(100.0)$ & $--(--)$ & $0.00(0.00----)$ & 0.999 & & \\
\hline \multicolumn{7}{|l|}{ Trimester } \\
\hline 1 & $65(95.6)$ & $3(4.4)$ & 1 & & 1 & \\
\hline 2 & $85(81.0)$ & $20(19.0)$ & $5.10(1.45-17.90)$ & 0.011 & $5.61(1.40-22.45)$ & 0.015 \\
\hline 3 & $83(95.4)$ & $4(4.6)$ & $1.04(0.23-4.83)$ & 0.956 & $0.80(0.15-4.18)$ & 0.789 \\
\hline \multicolumn{7}{|l|}{ Parity } \\
\hline Nullipara & $43(93.5)$ & $3(6.5)$ & $0.35(0.10-1.26)$ & 0.107 & $0.36(0.09-1.53)$ & 0.168 \\
\hline Primary para & $105(93.8)$ & $7(6.2)$ & $0.33(0.13-0.84)$ & 0.020 & $0.47(0.17-1.30)$ & 0.146 \\
\hline \multicolumn{7}{|c|}{ History of catheterization } \\
\hline Yes & $7(63.6)$ & $4(36.4)$ & $5.61(1.53-20.63)$ & 0.009 & $2.57(0.51-13.06)$ & 0.255 \\
\hline
\end{tabular}




\begin{tabular}{|c|c|c|c|c|c|c|}
\hline \multirow[t]{2}{*}{ Variable } & \multicolumn{2}{|c|}{ Asymptomatic bacteriuria } & \multirow[t]{2}{*}{ COR $(95 \% \mathrm{CI})$} & \multirow[t]{2}{*}{ P-value } & \multirow[t]{2}{*}{ AOR (95\%CI) } & \multirow[t]{2}{*}{ P-value } \\
\hline & No Number (\%) & Yes Number (\%) & & & & \\
\hline No & $226(90.8)$ & $23(9.2)$ & 1 & & 1 & \\
\hline \multicolumn{7}{|l|}{ History of UTI } \\
\hline Yes & $13(56.5)$ & $10(43.5)$ & $9.95(3.81-26.02)$ & 0.000 & $12.47(3.91-39.82)$ & 0.000 \\
\hline No & $220(92.8)$ & $17(7.2)$ & 1 & & 1 & \\
\hline \multicolumn{7}{|l|}{ Marital status } \\
\hline Married & $229(90.2)$ & $25(9.8)$ & $4.58(0.80-26.27)$ & 0.088 & & \\
\hline Other & $4(66.6)$ & $2(33.4)$ & 1 & & & \\
\hline \multicolumn{7}{|l|}{ Residence } \\
\hline Urban & $185(89.4)$ & $22(10.6)$ & $1.14(0.41-3.17)$ & 0.799 & & \\
\hline Rural & $48(90.6)$ & $5(9.4)$ & 1 & & & \\
\hline \multicolumn{7}{|l|}{ Education } \\
\hline No formal education & $81(91.0)$ & $8(9.0)$ & $0.64(0.18-2.31)$ & 0.497 & & \\
\hline Write and read & $5(100)$ & $0(0)$ & $0.00(0.00----)$ & 0.999 & & \\
\hline Elementary (1-8) & $49(80.4)$ & $12(19.6)$ & $1.59(0.47-5.43)$ & 0.458 & & \\
\hline Secondary $(9-12)$ & $72(96.0)$ & $3(4.0)$ & $0.27(0.06-1.29)$ & 0.101 & & \\
\hline Higher education $(12+)$ & $26(86.7)$ & $4(13.3)$ & 1 & & & \\
\hline \multicolumn{7}{|l|}{ Occupation } \\
\hline Farmer & $42(87.5)$ & $6(12.5)$ & 1 & & & \\
\hline Government employee & $39(90.7)$ & $4(9.3)$ & $0.72(0.19-2.74)$ & 0.627 & & \\
\hline Student & $7(87.5)$ & $1(12.5)$ & $1.00(0.10-9.61)$ & 1.000 & & \\
\hline Unemployed & $12(100)$ & $0(0)$ & $0.00(0.00----)$ & 0.999 & & \\
\hline Housewife & $112(88.2)$ & $15(11.8)$ & $0.94(0.34-2.58)$ & 0.900 & & \\
\hline Private business & $21(95.5)$ & $1(4.5)$ & $0.35(0.04-3.10)$ & 0.346 & & \\
\hline
\end{tabular}

\subsection{Isolation and Identification of Bacterial Uropathogens}

Gram negative bacteria (63\%) was more abundant than the gram positive bacteria (37.0 \%) (Table 3). E. coli (37.0\%) was most prevalent and Proteus species (5.88\%) least prevalent isolate. E. coli $(37.0 \%)$ and S. aureus $(25.9 \%)$ were predominant gram negative and gram positive isolates respectively (Table 3).

Table 3. : Bacterial isolates and their frequency from urine culture in asymptomatic UTI in Pregnant women at Mizan-Aman town, South-western Ethiopia, from September-December of 2017.

\begin{tabular}{ll}
\hline Bacterial isolates & Total (\%) \\
\hline Escherichia coli & $10(37.0)$ \\
Klebsiella species & $3(11.2)$ \\
Pseudomonas aeruginosa & $3(11.2)$ \\
Proteus species & $1(3.70)$ \\
Staphylococcus aureus & $7(25.9)$ \\
Coagulase negative Staphylococci & $3(11.2)$ \\
Total & $27(100)$ \\
\hline
\end{tabular}

\subsection{Antimicrobial Susceptibility Pattern}

Eleven antimicrobial agents were used to determine the susceptibility pattern of the bacterial isolates. The rates of susceptibility of Gram- positives and gram negatives ranged between $10 \%-100 \%$ and $11.8 \%-94.1 \%$ respectively. Ciprofloxacin was most effective and ampicillin was the least effective antibiotic against both types of bacterial isolates i.e. gram positive and gram negative (Table 4 and table 5).

Multidrug resistance (resistance to two or more drugs) was identified $81.5 \%$ of the bacterial isolates from asymptomatic pregnant women. Gram negative (82.4\%) and gram positive (80\%) bacteria were multi-drug resistant (Table 6).

Table 4 Antibiotic susceptibility pattern of Gram positive bacterial isolates from urine culture in asymptomatic UTI in pregnant women (N=10) at MizanAman town, South-western Ethiopia, from September-December of 2017.

\begin{tabular}{|c|c|c|c|c|c|c|c|c|c|c|c|}
\hline \multirow{2}{*}{ Species of Bacteria } & \multicolumn{11}{|c|}{ Number (\%) of susceptible strains } \\
\hline & AMP & CRO & AMC & C & CIP & DO & CN & NA & $\mathbf{K}$ & SXT & CXT \\
\hline S. aures $(\mathrm{n}=7)$ & $0(0)$ & $4(57.1)$ & $4(57.1)$ & $4(57.1)$ & $7(100)$ & $2(28.6)$ & $4(57.1)$ & $2(28.6)$ & $7(100)$ & $6(85.7)$ & 4` (57.1) \\
\hline $\operatorname{CoNS}(\mathrm{n}=3)$ & $1(33.4)$ & $3(100)$ & $1(33.4)$ & $1(33.4)$ & $3(100)$ & $1(33.4)$ & $3(100)$ & $1(33.4)$ & $3(100)$ & $2(66.7)$ & $2(66.7)$ \\
\hline Total $(\mathrm{n}=10)$ & $1(10)$ & $7(70)$ & $5(50)$ & $5(50)$ & $10(100)$ & $3(30)$ & $7(70)$ & $3(30)$ & $7(100)$ & $8(80)$ & $6(60)$ \\
\hline
\end{tabular}

CoNS=Coagulase negative Staphylococci.

AMP: Ampicillin; AMC: Amoxicillin-Clavulanic acid; CRO: Ceftriaxone; C: Chloramphenicol; CIP: Ciprofloxacin; DO: Doxycycline; CN: Gentamicin; K: Kanamycin; SXT: Trimethoprim-sulphamethoxazole; CXT: Cefoxitin and NA: Nalidixic acid. 
Table 5. Antibiotic susceptibility pattern of Gram Negative bacterial isolates from urine culture in asymptomatic UTI in pregnant women (N=17) at MizanAman town, South-western Ethiopia, from September-December of 2017.

\begin{tabular}{|c|c|c|c|c|c|c|c|c|c|c|c|}
\hline \multirow{2}{*}{ Species of Bacteria } & \multicolumn{11}{|c|}{ Number of bacterial strains (\%) susceptible to antibiotic tested } \\
\hline & AMP & AMC & CRO & $\mathrm{C}$ & CIP & DO & $\mathbf{C N}$ & SXT & NA & $\mathbf{K}$ & CXT \\
\hline E. coli $(\mathrm{n}=10)$ & $2(20)$ & $7(70)$ & $5(50)$ & $5(50)$ & $10(100)$ & $4(40)$ & $6(60)$ & $8(80)$ & $4(40)$ & $7(70)$ & $8(80)$ \\
\hline $\begin{array}{l}\text { Klebsiella species } \\
(\mathrm{n}=3)\end{array}$ & $0(0)$ & $1(33.4)$ & $2(66.7)$ & $1(33.4)$ & $2(66.7)$ & $1(33.4)$ & $0(0)$ & $2(66.7)$ & $0(0)$ & $2(66.7)$ & $3(100)$ \\
\hline$P$. aeruginosa $(\mathrm{n}=3)$ & $0(0)$ & $3(100)$ & $0(0)$ & $0(0)$ & $3(100)$ & $1(33.4)$ & $3(100)$ & $2(66.7)$ & $0(0)$ & $0(0)$ & $0(0)$ \\
\hline Proteus species $(\mathrm{n}=1)$ & $0(0)$ & $1(100)$ & $1(100)$ & $0(0)$ & $1(100)$ & $1(100)$ & $1(100)$ & $1(100)$ & $1(100)$ & $1(100)$ & $1(100)$ \\
\hline Total $(n=17)$ & $2(11.8)$ & $\begin{array}{l}12 \\
(70.6)\end{array}$ & $8(47.0)$ & $6(35.3)$ & $\begin{array}{l}16 \\
(94.1)\end{array}$ & $7(41.1)$ & $\begin{array}{l}10 \\
(58.8)\end{array}$ & $\begin{array}{l}13 \\
(76.5)\end{array}$ & $5(29.4)$ & $\begin{array}{l}10 \\
(58.8)\end{array}$ & $\begin{array}{l}12 \\
(70.6)\end{array}$ \\
\hline
\end{tabular}

AMP: Ampicillin; AMC: Amoxicillin-Clavulanic acid; CRO: Ceftriaxone; C: Chloramphenicol; CIP: Ciprofloxacin; DO: Doxycycline; CN: Gentamicin; K: Kanamycin; SXT: Trimethoprim-sulphamethoxazole; CXT: Cefoxitin and NA: Nalidixic acid.

Table 6. Multidrug resistance pattern of bacterial isolates from urine culture in asymptomatic UTI in pregnant women (N=27) at Mizan-Aman town, Southwestern Ethiopia, from September-December of 2017.

\begin{tabular}{|c|c|c|c|c|c|c|c|}
\hline \multicolumn{8}{|l|}{ Antimicrobial pattern } \\
\hline Bacterial isolate & Total (\%) & R0 & R1 & $\mathbf{R 2}$ & R3 & R4 & $\geq \mathrm{R5}$ \\
\hline Gram negative & $17(63.0)$ & $0(0)$ & $3(17.6)$ & $0(0)$ & $1(5.9)$ & $3(17.6)$ & $10(58.8)$ \\
\hline Escherichia coli & $10(58.8)$ & $0(0)$ & $2(20)$ & $0(0)$ & $0(0)$ & $3(30)$ & $5(50)$ \\
\hline Klebsiella species & $3(17.6)$ & $0(0)$ & $0(0)$ & $0(0)$ & $1(33.3)$ & $0(0)$ & $2(66.7)$ \\
\hline Pseudomonas aeruginosa & $3(17.6)$ & $0(0)$ & $0(0)$ & $0(0)$ & $0(0)$ & $0(0)$ & $3(100)$ \\
\hline Proteus species & $1(5.9)$ & $0(0)$ & $1(100)$ & $0(0)$ & $0(0)$ & $0(0)$ & $0(0)$ \\
\hline Gram Positive & $10(37.0)$ & $0(0)$ & $2(20)$ & $1(10)$ & $0(0)$ & $1(10)$ & $6(60)$ \\
\hline Staphylococcus aureus & $7(70)$ & $0(0)$ & $1(14.3)$ & $1(14.3)$ & $0(0)$ & $1(14.3)$ & $4(57.1)$ \\
\hline Coagulase negative staphylococci & $3(30)$ & $0(0)$ & $1(33.3)$ & $0(0)$ & $0(0)$ & $0(0)$ & $2(66.7)$ \\
\hline Total & $27(100)$ & $0(0)$ & $5(18.5)$ & $1(3.7)$ & $1(3.7)$ & $4(14.8)$ & $16(59.3)$ \\
\hline
\end{tabular}

R0- No antibiotic resistance, R1- Resistance to one, R2-Resistance to two, R3-Resistance to three, R4- Resistance to four, $\geq$ R5- resistance to five and more drugs.

\section{Discussions}

The findings reinstated the working hypothesis about the locale specific prevalence rate of ASB, types of bacteria causing ASB and their differential susceptibility pattern among pregnant women. Globally, the prevalence rate of $3.6 \%-37.1 \%$ has been reported [23-24]. The prevalence of ASB among pregnant women in this study was within the national range (7\%-18.8\%) reported in Ethiopian women of other regions [19, 25-27]. This difference may be related to geographical location, environmental conditions, social and personal hygiene and/or negligence of ASB by the health care system. This preliminary prevalence in double digit indicates neglect of ASB related health issues in this South Ethiopian region. The course correction measures may be implemented. The numbers of bacterial species involved in ASB have a geographical outline. As against our finding of six bacterial isolates, previous literatures on Ethiopian populations enlist 5-9 bacterial species causing ASB [17, 28-29]. The literature is not unanimous on the most prevalent bacteria even in Ethiopian population. Though majority of the studies including our work found $E$ Coli to be the most prevalent in causing ASB [12, 17, 28-31]. The physio-anatomical changes and difficulty in personal hygiene maintenance during pregnancy may increase the risk of urogenital colonization by $E$. coli. Moreover increased level of amino acids and lactose during pregnancy encourage growth of E. coli [30-31]. Coagulase negative Staphylococcus (32.6\%) was found to be the leading cause of ASB in Hawassa region [26]. Most of the previous studies failed to identify infection by Proteus species in Ethiopians pregnant women [19, 28, 31-32]. This regional pattern with respect to the types, number, and most prevalent bacteria causing ASB highlight the challenge in managing it.

Similar to previous reports, place of residence, gravidity, occupation, and marital status was not found to be associated with ASB (Table 2) [31, 33]. However, there are contradictory evidences regarding relationship between maternal age and ASB [29-32, 34-35]. Some studies reported association with increasing age [34], while others found it to be related with younger age group [30-31]. This future studies should try to look into the aspect. In our study, contrary to previous studies in Ethiopia [19, 26, 31], trimester (gestational age) was associated with prevalence of ASB. Pregnant women in second trimester had high likelihood of testing positive for significant bacteriuria $(p<0.05)$ compared to pregnant women in the first trimester. This susceptibility during this period may be related to ureteral dilatation. The dilatation stimulates production of progesterone and estrogen which lowers the tone of the uterus $[12,36]$. Similar to previous findings, the prevalence of ASB in pregnant women was associated with history of UTI $(p<0.001)[19,31]$. The presence of resistant strains may be implicated in this relationship.

Antimicrobial resistance is an area of increasing concern in the management of UTI [31-32]. The prescription of antibiotics without proper test of susceptibility is a contributing factor. The drugs with higher susceptibility 
should be used for management of ASB. Therefore, Ciprofloxacin, kanamycin and trimethoprimsulphamethoxazole may be prescribed in this South western Ethiopian pregnant women population to manage ASB caused by gram positive bacteria (Table 4). Ciprofloxacin, trimethoprim- sulphamethoxazole, amoxicillin-clavulnic acid and cefoxitin may be used to manage ASB caused by gram negative bacteria, because of the higher susceptibility bacteria to these antibiotics. The higher resistance for ampicillin (88.2\%), nalidixic acid (70.6\%) and chloramphenicol $(64.7 \%)$ is similar to previous reports [15]. Earlier exposure of the isolates to these drugs may be related to increased resistance development. Similar to previous reports, multi drug resistance $(\mathrm{MDR}=$ resistance to $\geq 2 \mathrm{drugs}$ ) was observed in the overwhelming majority $(81.5 \%)$ of the bacterial isolate (Table 6) [19, 31-32]. The prescription of antibiotics without susceptibility pattern analysis and unregulated over-the-counter sale of antibiotics are most likely reason for increasing resistance.

\section{Conclusion}

In generally, pregnant women with ASB may have serious consequences on both mother and fetus. Since in this study the locale specific heterogeneity in ASB prevalence, type and number of bacterial species, dominant bacterial species, antibiotic susceptibility pattern and multidrug resistance was observed. Proper clinical management of ASB depends on locale specific information like prevalence; type and number of bacterial species, dominant bacterial species, antibiotic susceptibility pattern and multidrug resistance. Therefore, it is important to screen all antenatal women for asymptomatic bacteriuria at their first prenatal visit; preferably in first trimester as well as antimicrobial susceptibility testing should be performed for management of ASB among pregnant women.

\section{Data Availability}

All relevant data are within the article, but any additional data required are available from the corresponding author upon request.

\section{Ethical Approval}

Ethical approval and clearance letter of permission were obtained from ethical clearance committee of College of Health Science and Medicine, Mizan-Tepi University. An official letter written from Mizan-Tepi University Teaching Hospital Chief Executive Office was distributed to each study ward and area.

\section{Conflict of Interest}

All the authors do not have any possible conflicts of interest.

\section{Acknowledgements}

Our earnest gratitude goes to the staff of Mizan-Tepi University teaching hospital for their technical assistance and kind cooperation during specimen collection. Special thanks also to all the study participants for their cooperation during data and sample collection.

\section{Authors' Contributions}

AK conceived, designed, performed data collection, data analysis, drafted the manuscript. MT interpreted the results, reviewed and approved the manuscript. AK drafted the manuscript.

\section{References}

[1] Seseon NI, Garingalo-molina FD, Yeasiano CJ. Prevalence of asymptomatic bacteriuria and associated risk factors in pregnant women. Phil J Microbial Infect Dis. 2003; 32: 639.

[2] Greva M, Biswas KM, Perloff D. Cardiac, Haematologic, Pulmonary, Renal and Urinary Tract Disorders in Pregnancy. USA: In: DeCherney AH, Nathan L; editors. Current obstetrics and gynecologic diagnosis and treatment. New York McGraw-Hill; 2003; 315-325.

[3] Rahimkhani M, Khavari-Daneshvar H, Sharifian R. ASYMPTOMATIC BACTERIURIA AND PYURIA IN PREGNANCY Acta Medica Iranica. 2008; 46 (5): 409-12.

[4] Lucas MJ, Cunningham GF. Urinary infection in pregnancy. Clinical Obstetrics and Gynaecology 1993; 3 (4): 855-68.

[5] Duarte G, Marcolin AC, Quintana SM, Cavalli RC. Urinary tract infection in pregnancy. Rev Bras Ginecol Obstet Gynecol. 2002; 30 (2): 93-100.

[6] Moges F, Genetu A, Mengistu G. Antibiotic sensitivities of common bacterial pathogens in urinary tract infections at Gondar hospital, Ethiopia. East Afr Med J 200279 (3): 140-2.

[7] Al-Haddad AM. Urinary Tract Infections in Pregnancy in AlMukalla District, Yemen. East Mediterr Health Journal. 2005; 11 (3): 505-10.

[8] COlgAN R, NiCOLle LE, MCGLONE A, HOOTON TM. Asymptomatic Bacteriuria in Adults. American Family Physician. 2006; 74 (6): 985-90.

[9] Celen S, Oruc A, Karayalcin R, Saygan S, S U, B P. Asymptomatic Bacteriuria and Antibacterial Susceptibility Patterns in an Obstetric Population. ISRN Obstet Gynaecol. 2011: Article ID 721872.

[10] Roony C. Antenatal care and maternal health: how effective is it? Maternal Health and Safe Motherhood Programme, Division of Family Health. In: World Health Organization, editor. 1992.

[11] Mukherjee K, Golia S, CL V, Babita, Bhattacharjee D, Chakroborti G. A study on asymptomatic bacteriuria in pregnancy: prevalence, etiology and comparison of screening methods. International Journal of Research in Medical Sciences. 2014; 2: 1085-91. 
[12] Dalzell J, Lefevre M. Urinary tract infection of pregnancy. American Academy of Family Physicians. 2000; 61: 713-21.

[13] Marahatta R, Dhungel BA, Pradhan P, Rai S, Choudhury DR. Asymptomatic bacteriurea among pregnant women visiting Nepal Medical College Teaching Hospital, Kathmandu, Nepal. Nepal Med Coll J 2011; 13 (2): 107-10.

[14] Nicolle LE, Bradley S, Colgan R, Rice JC, Schaeffer A, Hooton TM. Infectious Disease Society of America guidelines for the diagnosis and treatment of asymptomatic bacteruria in adults. Clin Infect Dis. 2005; 40: 643-54

[15] Demilie T, Beyene G, Melaku S, Tsegaye W. Urinary Bacterial Profile And Antibiotic Susceptibility Pattern Among Pregnant Women In North West Ethiopia. Ethiop J Health Sci. 2012; 22: $121-8$.

[16] Imade PE, Izekor PE, Eghafona NO, Enabulele OI, Ophori E. Asymptomatic bacteriuria among pregnant women. North American Journal of Medical Sciences 2010; 2 (6): 263-6.

[17] Obirikorang C, Quaye L, Bio FY, Amidu N, Acheampong I, Addo K. Asymptomatic Bacteriuria among Pregnant Women Attending An-tenatal Clinic at the University Hospital, Kumasi, Ghana. Journal of Medical and Biomedical Sciences. 2012; 1: 38-44.

[18] Mokube MN, Atashili J, Halle-Ekane GE, Ikomey GM, Ndumbe PM. Bacteriuria amongst Pregnant Women in the Buea Health District, Cameroon: Prevalence, Predictors, Antibiotic Susceptibility Patterns and Diagnosis. . PLoS ONE 2013; 8 (8): e71086.

[19] Ferede G, Yismaw G, Wondimeneh Y, Sisay Z. The Prevalence and Antimicrobial Susceptibility pattern of Bacterial Uropathogens Isolated from pregnant women. European Journal of Experimental Biology. 2012; 2: 1497502 .

[20] Smaill F, Vazquez JC. Antibiotics for asymptomatic bacteriuria in pregnancy. Cochrane Database of Systematic Reviews. 2004.

[21] Cheesbrough M, editor. District laboratory practice in tropical countries. $2^{\text {nd }}$ ed. Cambridge, Cambridge University press 2006 .

[22] Institute Clinical Laboratory Science. Performance Standards for Antimicrobial Susceptibility Testing; Twenty-First Informational Supplement. M100-S21 Wayne, Pennsylvania 19087 USA, 2011. p. 41-122.

[23] Tosin OJA, Mathew AO, Bello FJ, Oludare IT, Dolapo AL, Abosede AF. Asymptomatic Bacteriuria among antenatal Women Attending private Hospital in Lagos, Nigeria. Scholars Journal of Applied Medical Sciences (SJAMS). 2014; 2: 307680 .

[24] Jennifer P, Cyril R, Piyumi P, Nimesha G, Renuka J.
Asymptomatic Bacteriuria in Pregnancy: Prevalence, Risk factors and Causative Organisms. Sri Lankan Journal of Infectious Diseases. 2012; 1: 42-6.

[25] Gabre-Selassie S. Asymptomatic bacteriuria in pregnancy; epidemiological clinical and microbiological approach. Ethiop Med J 1998; 36: 185-92.

[26] Tadesse E, Teshome M, Merid Y, Kibre B, Shimelis1 T. Asymptomatic urinary tract infection among pregnant women attending the antenatal clinic of Hawassa Referral Hospital, Southern Ethiopia. BMC Research Notes. 2014; 7: 155.

[27] Tadesse A, Negash M, Ketema LS. Asymptomatic bacteriuria in pregnancy: assessment of prevalence, microbial agents and their antimicrobial sensitivity pattern in Gondar Teaching Hospital, North West Ethiopia. Ethiop Med J 2007; 45: 143-9.

[28] Nisha AK, Etana AE, Tesso H. Prevalence of asymptomatic bacteriuria during pregnancy in Adama city, Ethiopia. International Journal of Microbiology and Immunology Research. 2015; 3: 058-63.

[29] Turpin CA, Minkah B, Danso KA, Frimpong1 EH. Asymptomatic Bacteriuria In Pregnant Women At-Tending Antenatal Clinic At Komfo Anokye Teaching Hospital, Kumasi, Ghana. Ghana Medical Journal. 2007; 41: 1.

[30] Jazayeri A, Irajian G. Asymptomatic Urinary Tract Infection in Pregnant Women. Iranian Journal of Pathology 2009; 4: 105-8.

[31] Alemu A, Moges F, Shiferaw Y, Tafess K, Kassu A, Anagaw $\mathrm{B}$, et al. Bacterial profile and drug susceptibility pattern of urinary tract infection in pregnant women at University of Gondar Teaching Hospital, Northwest Ethiopia. BMC Research Notes. 2012; 5: 197.

[32] Assefa A, Asrat D, Woldeamanuel Y, G/Hiwot Y, Abdella A, Melesse T. Bacterial profile and drug susceptibility pattern of urinary tract infection in pregnant women at Tikur Anbessa Specialized Hospital Addis Ababa, Ethiopia. Ethiopia Medical Journal 2008; 46: 227-35.

[33] Hamdan HZ, Ziad AHM, Ali SK, Adam I. Epidemiology of urinary tract infections and antibiotics sensitivity among pregnant women at Khartoum North Hospital. Annals of Clinical Microbiology and Antimicrobials. 2011; 10: 2.

[34] Tugrul S, Oral O, Kumru P, Kose D, Alkan A, Yildirim G. Evaluation and importance of asymptomatic bacteriuria in pregnancy. Clin Exp Obstet Gynecol. 2005; 32: 237-40.

[35] G A, J B. Microbial aetiology and sensitivity of asymptomatic bacteriuria among ante-natal mothers in Mulago hospital, Uganda. African Health Sciences. 2010; 10 (4): 349 - 52.

[36] Vaijanathrao CY, Nalini YL, Reddy CM. Antibiotic Sensitivity Pattern of Uropathogens: A Comparative Study between Symptomatic and Asymptomaic Bacteriuria in Pregnant Women. IntJCurrMicrobiolAppSci. 2015; 4: 689-95. 